\title{
EVALUASI STATUS KESUBURAN PADA BEBERAPA JENIS TANAH DI LAHAN KERING KABUPATEN PIDIE PROVINSI ACEH
}

( The Evaluation of Soil Fertility Status in Saveral of soil type Drylands of Pidie Dystrics)

\author{
Maulia Rahmat Husni ${ }^{1}$, Sufardi ${ }^{2}$, Munawar Khalil ${ }^{2}$ \\ ${ }^{1}$ Program Studi Agroteknologi, Fakultas Pertanian, Universitas Syiah Kuala \\ ${ }^{2}$ Program Studi Ilmu tanah, Fakultas Pertanian, Universitas Syiah Kuala
}

\begin{abstract}
Abstrak. Penelitian ini bertujuan mengevaluasi status kesuburan tanah pada beberapa jenis tanah di lahan kering Kabupaten Pidie, Provinsi Aceh. Penelitian ini dilaksanakan pada Juni hingga November 2015. Metode yang digunakan adalah metode deskriptif melalui survei di lapangan dan analisis di Laboratorium. Pengambilan sampel dengan melakukan pada areal survei secara sekuen bergerak yang diperkirakan sifat tanahnya berbeda berdasarkan ketinggian tempat, tanah diambil pada kedalaman top soil $(0-20) \mathrm{cm}$. Parameter kimia tanah yang di analisis yaitu ; $\mathrm{C}$ organik, $\mathrm{P}_{2} \mathrm{O}_{5}$ total, $\mathrm{K}_{2} \mathrm{O}$ total, KTK, KB. Penentuan status kesuburan berpedoman pada Pusat Penelitian Tanah PPT, Bogor (1995). Sampel tanah dianalisis di Laboratorium Penelitian Tanah dan Tanaman Fakultas Pertanian Universitas Syiah Kuala, Banda Aceh dan Laboratorium Penelitian Tanah Balai Besar Sumber daya Lahan Pertanian (BBSDL) Bogor. Hasil penelitian menunjukkan status kesuburan lahan kering setiap jenis tanahnya adalah rendah. Parameter kesuburan yang menjadi kendala dalam status kesuburan tanah pada setiap jenis tanahnya di lahan kering Kabupaten Pidie dalah C-organik tanah dan Kejenuhan basa yang rendah.
\end{abstract}

Kata kunci : Lahan kering, Kesuburan, Tanah, Analisis

\begin{abstract}
This study aimed to evaluate the status of soil fertility in some types of soil in upland districts of Pidie, Aceh province. The research was conducted from June to November 2015. The method used is descriptive method through the field survey and analysis in the laboratory. Sampling by the areal survey estimated sequentially moving soil properties vary based on altitude, soil taken at a depth of top soil $(0-20) \mathrm{cm}$. Soil chemical parameters were analyzed, namely; Organic C, total $\mathrm{P}_{2} \mathrm{O}_{5}, \mathrm{~K}_{2} \mathrm{O}$ total, CEC, KB. Fertility status determination based on the Land Research Center PPT, Bogor (1995). Soil samples were analyzed at the Laboratory of Soil and Plant Research Faculty of Agriculture, University of Syiah Kuala, Banda Aceh and Soil Research Laboratory of the Center for Agricultural Land Resources (BBSDL) Bogor. The results showed the fertility status of dryland every type of soil is low. Parameter fertility become an obstacle in the soil fertility status on any type of soil in upland districts of Pidie dalah C-organic soil and low base saturation.
\end{abstract}

Keywords: Soil Fertility, Survey, Dry Land, Soil Type

\section{PENDAHULUAN}

Hambatan utama dalam pemanfaatan lahan kering untuk pertanian adalah rendahnya tingkat kesuburan tanah yang disebabkan oleh adanya sejumlah kendala kimia yang membatasi pertumbuhan tanaman seperti masalah kemasaman dan ketersediaan hara. Menurut Abdurachman et al., (2008) lahan kering memiliki tingkat kesuburan tanah yang rendah, dan kadar bahan organik rendah. Kondisi ini makin diperburuk dengan terbatasnya penggunaan pupuk organik, terutama pada tanaman pangan semusim. Di samping itu, secara alami kadar bahan organik tanah di daerah tropis cepat menurun, mencapai 30-60\% dalam waktu 10 tahun (Brown 
dan Lugo 1990 dalam Suriadikarta et al., 2002). Maka diperlukan usaha pengelolaan tanah yang baik ( berdasarkan dari parameter kesuburan kimia tanah) artinya sesuai dengan kebutuhan untuk jenis tanaman yang dibudidayakan. Untuk merumuskan tindakan yang tepat agar tujuan tersebut dapat dicapai, maka perlu diketahui terlebih status kesuburan tanah, sehingga dapat diketahui sifat kimia tanah yang menjadi faktor pembatas pada setiap daerah, hal tersebut dapat dilakukan dengan mengevaluasi kesuburan tanah hal ini merupakan diagnosaan masalah keharaan dalam tanah serta menentukan jenis dan jumlah unsur hara yang diperlukan (pemupukan). Salah satu cara yang sering digunakan dalam menilai kesuburan suatu tanah adalah melalui pendekatan dengan analisis tanah atau uji sampel tanah. Secara umum uji tanah adalah suatu kegiatan analisis kimia di laboratorium yang sederhana, cepat, murah, tepat, dan dapat diulang (reproduceable) untuk menduga ketersediaan unsur hara. Uji tanah dalam arti luas yaitu menyangkut aspek-aspek intrpretasi, evaluasi dan penyusunan rekomendasi pupuk dari hasil uji tanah serta pengambilan sampel tanah (Melsted and Peck, 1972).

Terdapat lima parameter tanah yang digunakan dalam penelitian ini untuk menilai status kesuburan tanah. (PTT, 1995) mengemukakan bahwa untuk menetapkan status kesuburan tanah maka diperlukan parameter sifat kimia tanah seperti; Kapasitas Tukar Kation, Kejenuhan Basa, C-organik, Kadar P dan K total tanah. Kadar unsur hara tanah yang diperoleh dari data analisis tanah bila dibandingkan dengan kebutuhan unsur hara masing- masing tanaman, maka dapat diketahui apakah status unsur hara dalam tanah tersebut sangat rendah, rendah sedang dan tinggi sesuai kriteria tertentu berdasarkan petunjuk teknis penentuan status kesuburan berpedoman pada Pusat Penelitian Tanah PPT, Bogor (1995).

Berdasarkan uraian pemikiran diatas, maka perlu dilakukan evaluasi status kesuburan tanah, pada beberapa lokasi lahan kering di Kabupaten Pidie sehingga dapat diketahui teknologi apa yang bisa diterapkan para petani untuk menunjang peningkatan produksi khusnya petani lahan kering dalam peningkatan penyediaan dan ketahanan pangan untuk Kabupaten Pidie. Itulah sebabnya mengetahui status kesuburan merupakan hal penting dan berpengaruh terhadpa pertanian dimasa yang akan datang.

\section{Lokasi dan Waktu}

\section{METODE PENELITIAN}

Penelitian ini dilaksanakan di Kabupaten Pidie tepatnya di wilayah Kecamatan Padang tiji meliputi Desa Jok Tanjung terdapat jenis tanah Kambisol Humik, Desa Kupula terdapat jenis tanah Aluvial Distrik, Desa Rungkom terdapat jenis tanah Gelisol Distrik. Kecamatan Delima meliputi Desa Lhee Meunasah terdapat jenis tanah Gleisol Distrik. Kecamatan Muara Tiga Desa Gampong Paud terdapat jenis tanah Kambisol Distrik. Kecamatan Batee meliputi Desa Dayah Tuha terdapat jenis tanah Gleisol Distrik, Desa Kareung terdapat jenis tanah Regosol Eutrik, lokasi Glee Guha Tujuh terdapat jenis tanah Renzina. Provinsi Aceh. Untuk analisis sifat kimia tanah dilakukan di Laboratorium Penelitian Tanah dan Tanaman Fakultas Pertanian Universitas Syiah Kuala dan Laboratorium Penelitian Tanah BBSDL (Balai Besar Sumber daya Lahan Pertanian) Bogor. Adapun penelitian ini dilakukan pada bulan Juni sampai 
November 2015. Peralatan yang digunakan meliputi : GPS (global Positioning System), cangkul, bor tanah, $\mathrm{pH}$ tancap, kantong plastik, kertas label, daftar/form isian keragaan di lapangan, hand board, Alat tulis dan untuk pemetaan menggunakan software Arc-GIS version 10.2. Bahan yang digunakan dalam penelitian ini adalah : bahan-bahan yang digunakan untuk uji sampel dilapangan adalah aquades 0,5 N HCl, larutan peroksida $\left(\mathrm{H}_{2} \mathrm{O}_{2}\right) 10$ dan $30 \%$ dan bahan bahan lain yang diperlukan untuk analisis tanah di laboratorium.

\section{Metode Pelaksanaan Penelitian}

Penelitian ini merupakan penelitian deskriptif kualitatif fenomenologis (mulyana, 2003) dengan survai lahan dan didukung analisis laboratorium secara kualitatif. Pengambilan sampel tanah di lahan kering Kabupaten Pidie hanya di fokuskan pada lahan pertanian tanaman semusim, yaitu sawah tadah hujan atau kebun. Pengambilan sampel tanah dilakukan pada areal survei secara sekuen berdasarkan tempat diperkirakan sifat tanahnya berbeda, maka hasil analisis tanah yang diperoleh diharapkan dapat mencerminkan nilai sebenarnya. Tahap ini sebelumnya telah dilakukan penetuan lokasi atau desa yang terdiri dari beberapa kecamatan pada lahan kering yang berada di wilayah Kabupaten Pidie dengan merujuk pada peta administrasi Kabupaten Pidie. Pengambilan sampel tanah diambil pada lapisan atas pada kedalaman top soil $0-20 \mathrm{~cm}$ dan dilakukan perekaman titik koordinat dengan menggunakan GPS (global Positioning System). Sedangkan informasi pengelolaan tanah diperoleh dengan cara pengamatan langsung dilapangan dan wawancara dengan petani secara mendalam secara snow ball yang bertujuan untuk memperoleh informasi yang lengkap dari petani (Kusuma, 2005). Sampel-sampel tanah yang telah diambil dilapangan, selanjutnya dianalisis di laboratorium. Sifat-sifat kimia tanah yang dianalisis dilaboratorium C-organik ( metode Walkley and Black); KTK (metode $1 \mathrm{~N} \mathrm{NH4OAC} \mathrm{pH} \mathrm{7);}$ Kejenuhan Basa (Kation Basa/KTK*100\%); $\mathrm{P}_{2} \mathrm{O}_{5}$ total (metode Ekstraksi $\mathrm{HCl}$ 25\%); $\mathrm{K}_{2} \mathrm{O}$ (metode Ekstraksi $\mathrm{HCl} 25 \%$ ) (BPT, 2009). Untuk mengetahui sifatsifat kimia tanah dengan kriteria tertentu yang telah ditentukan. Berdasarkan Petunjuk Teknis Evaluasi Kesuburan Tanah (PPT,1995) yang disajikan pada Tabel 1.

Tabel . 1 Kriteria Penilaian Sifat Kimia Tanah

\begin{tabular}{cllllll}
\hline No & \multicolumn{1}{c}{ Soil Parameter } & \multicolumn{1}{c}{$\mathrm{S} \mathrm{R}$} & \multicolumn{1}{c}{$\mathrm{R}$} & \multicolumn{1}{c}{$\mathrm{S}$} & \multicolumn{1}{c}{$\mathrm{T}$} & \multicolumn{1}{c}{ ST } \\
\hline 1 & C organik (\%) & $<1,00$ & $1,00-2,00$ & $2,01-3,00$ & $3,01-5,00$ & $>5,00$ \\
2 & Kejenuhan Basa (\%) & $<20$ & $20-35$ & $36-50$ & $51-70$ & $>70$ \\
3 & $\mathrm{P}_{2} \mathrm{O}_{5} \mathrm{HCl} 25 \%$ & $<10$ & $10-20$ & $21-40$ & $41-60$ & $>60$ \\
4 & $\mathrm{~K}_{2} \mathrm{O} \mathrm{HC}$ $25 \%$ & $<10$ & $10-20$ & $21-40$ & $41-60$ & $>60$ \\
5 & $\mathrm{KTK}(\mathrm{me} / 100 \mathrm{~g})$ & $<5$ & $5-15$ & $17-24$ & $25-40$ & $>40$ \\
\hline
\end{tabular}

Ket;SR/R/S/T/ST; Sangat Rendah/Rendah/Sedang/Tinggi/Sangat Tinggi

Sumber: (PPT Bogor, 1995)

\section{Interpretasi data}

Data primer (data analisis) diperoleh dari hasil analisis tanah di laboratorium diharkatkan menurut pengharkatan kesuburan tanah PPT Bogor (1995). Sehingga diketahui harkat parameter kesuburan kimia tanah termasuk kedalam status rendah, sedang dan tinggi dapat dilihat pada Tabel 2 . 
Tabel 2. Kriteria Penilaian Status Kesuburan Tanah

\begin{tabular}{|c|c|c|c|c|}
\hline NO & KTK & $\mathrm{KB}$ & $\mathrm{P}_{2} \mathrm{O}, \mathrm{K}_{2} \mathrm{O}, \mathrm{C}$ organik & Status Kesuburan \\
\hline 1 & $\mathrm{~T}$ & $\mathrm{~T}$ & 2 T Tanpa R & Tinggi \\
\hline 2 & $\mathrm{~T}$ & $\mathrm{~T}$ & $2 \mathrm{~T}$ Dengan $\mathrm{R}$ & Sedang \\
\hline 3 & $\mathrm{~T}$ & $\mathrm{~T}$ & 2 S Tanpa R & Tinggi \\
\hline 4 & $\mathrm{~T}$ & $\mathrm{~T}$ & $2 \mathrm{~S}$ Dengan $\mathrm{R}$ & Sedang \\
\hline 5 & $\mathrm{~T}$ & $\mathrm{~T}$ & TSR & Sedang \\
\hline 6 & $\mathrm{~T}$ & $\mathrm{~T}$ & 2 R Dengan $T$ & Sedang \\
\hline 7 & $\mathrm{~T}$ & S & 2 R Dengan $S$ & Rendah \\
\hline 8 & $\mathrm{~T}$ & $S$ & 2 T Tanpa R & Tinggi \\
\hline 9 & $\mathrm{~T}$ & $S$ & 2 T Dengan $\mathrm{R}$ & Sedang \\
\hline 10 & $\mathrm{~T}$ & $S$ & 2 S Tanpa R & Sedang \\
\hline 11 & $\mathrm{~T}$ & $S$ & Kombinasi Lain & Rendah \\
\hline 12 & $\mathrm{~T}$ & $\mathrm{R}$ & 2 T Tanpa R & Sedang \\
\hline 13 & $\mathrm{~T}$ & $\mathrm{R}$ & 2 T Dengan $\mathrm{R}$ & Rendah \\
\hline 14 & $\mathrm{~T}$ & $\mathrm{R}$ & Kombinasi Lain & Rendah \\
\hline 15 & S & $\mathrm{T}$ & 2 T Tanpa R & Sedang \\
\hline 16 & S & $\mathrm{T}$ & $2 \mathrm{~T}$ Dengan $\mathrm{R}$ & Sedang \\
\hline 17 & S & $\mathrm{T}$ & Kombinasi Lain & Rendah \\
\hline 18 & S & S & 2 T Tanpa R & Sedang \\
\hline 19 & S & $S$ & 2 T Dengan $\mathrm{R}$ & Sedang \\
\hline 20 & S & $S$ & Kombinasi Lain & Rendah \\
\hline 21 & S & $\mathrm{R}$ & $3 \mathrm{~T}$ & Sedang \\
\hline 22 & S & $\mathrm{R}$ & Kombinasi Lain & Rendah \\
\hline 23 & $\mathrm{R}$ & $\mathrm{T}$ & 2 T Tanpa R & Sedang \\
\hline 24 & $\mathrm{R}$ & $\mathrm{T}$ & 2 T Dengan $\mathrm{R}$ & Rendah \\
\hline 25 & $\mathrm{R}$ & $\mathrm{T}$ & $2 \mathrm{~S}$ Tanpa R & Sedang \\
\hline 26 & $\mathrm{R}$ & $\mathrm{T}$ & Kombinasi Lain & Rendah \\
\hline 27 & $\mathrm{R}$ & $S$ & 2 T Tanpa R & Sedang \\
\hline 28 & $\mathrm{R}$ & S & Kombinasi Lain & Rendah \\
\hline 29 & $\mathrm{R}$ & $\mathrm{R}$ & Semua Kombinasi & Rendah \\
\hline 30 & SR & TSR & Semua Kombinasi & Sangat Rendah \\
\hline
\end{tabular}

SR/R/S/T/SR/TSR= Sangat Rendah/Rendah/Sedang/Tinggi/Tinggi/Sedang Rendah

Sumber: (PPT Bogor, 1995)

\section{HASIL DAN PEMBAHASAN}

Hasil Pengukuran parameter kesuburan tanah dan status kesuburan tanah pada beberapa jenish taha di lahan kering Kabupaten Pidie disajikan pada Tabel 1. 
Tabel 3. Hasil Evaluasi Status Kesuburan Tanah di lokasi penelitian

\begin{tabular}{|c|c|c|c|c|c|c|c|}
\hline \multirow[b]{2}{*}{ NO } & Macam Tanah & KTK & KB & $\mathrm{P}_{2} \mathrm{O}_{5}$ total & $\mathrm{K}_{2} \mathrm{O}$ & $\begin{array}{c}\mathrm{C} \\
\text { organik }\end{array}$ & \multirow{2}{*}{$\begin{array}{c}\text { Status } \\
\text { Kesuburan }\end{array}$} \\
\hline & SN 2014 & $\mathrm{me} / 100 \mathrm{~g}$ & $(\%)$ & $(\mathrm{Mg} / 100 \mathrm{~g})$ & $\begin{array}{c}(\mathrm{mg} / 100 \\
\mathrm{g})\end{array}$ & $(\%)$ & \\
\hline 1 & Kambisol & 51,47 (ST) & 0,16 & 92,00 (ST) & 98,67 & $2,03(\mathrm{R})$ & RENDAH \\
\hline 2 & $\begin{array}{l}\text { Kambisol } \\
\text { Distrik }\end{array}$ & $\begin{array}{l}41,13 \\
\text { (ST) }\end{array}$ & $\begin{array}{l}\text { CD } \\
0,07 \\
\text { (SR) }\end{array}$ & 46,00 (ST) & $\begin{array}{c}47,62 \\
(\mathrm{~T})\end{array}$ & $\begin{array}{l}1,51 \\
\text { (R) }\end{array}$ & RENDAH \\
\hline 3 & Alluvial Distrik & 34,27 (T) & $\begin{array}{l}0,08 \\
\text { (SR) }\end{array}$ & 71,33 (ST) & $\begin{array}{c}38,33 \\
(\mathrm{~S})\end{array}$ & $1,24(\mathrm{R})$ & RENDAH \\
\hline 4 & Gleisol Distrik & $\begin{array}{l}41,90 \\
\text { (ST) }\end{array}$ & $\begin{array}{l}0,12 \\
\text { (SR) }\end{array}$ & 64,13 (ST) & $\begin{array}{l}63,38 \\
\text { (ST) }\end{array}$ & $\begin{array}{l}0,75 \\
\text { (R) }\end{array}$ & RENDAH \\
\hline 5 & Regosol Eutrik & $25,20 \quad(\mathrm{~T})$ & $\begin{array}{l}0,31 \\
\text { (SR) }\end{array}$ & $\begin{array}{l}521,50 \\
\text { (ST) }\end{array}$ & $\begin{array}{l}170,0 \\
\text { (ST) }\end{array}$ & $\begin{array}{l}1,00 \\
\text { (R) }\end{array}$ & RENDAH \\
\hline 6 & Renzina & $\begin{array}{l}41,20 \\
\text { (ST) }\end{array}$ & $\begin{array}{l}0,08 \\
\text { (SR) }\end{array}$ & 77,60 (ST) & $\begin{array}{c}15,40 \\
(\mathrm{R})\end{array}$ & $\begin{array}{l}1,23 \\
\text { (R) }\end{array}$ & RENDAH \\
\hline
\end{tabular}

Keterangan; SR/R/S/T/ST; Sangat Rendah/Rendah/Sedang/Tinggi/SangatTinggi

Sumber: Hasil analisis laboratorium (data diolah, 2015)

Berdasarkan Petunjuk teknis Evaluasi Kesuburan Tanah (PPT, 1995) Bogor

\section{Kapasitas Tukar Kation (KTK) Tanah}

Kapasitas tukar kation (KTK) merupakan indiator kesuburan tanah. Tanah dilokasi penelitian di lahan kering Kabupaten Pidie memiliki nilai kapasitas tukar kation bervariasi pada setiap jenis tanahnya dari sedang sampai sangat tinggi dengan nilai rata-rata tertinggi $51,47 \mathrm{me} / 100 \mathrm{~g}$ sampai $25,20 \mathrm{me} / 100 \mathrm{~g}$. Tingginya nilai KTK tanah dilokasi penelitian diduga dipengaruhi oleh banyak kandungan fraksi liat yang lebih dominan. Menurut Sukisno et., al (2011) nilai KTK tinggi juga dipengaruhi oleh kadar liat, karena tanah yang didominasi oleh fraksi liat memiliki kapasitas pertukaran ion dan memegang air yang tinggi, oleh karena itu tanah yang didominasi oleh faksi liat memiliki stabilitas agregat yang tinggi karena adanya ikatan dalam partikel tanah.

\section{Kejenuhan Basa (KB) Tanah}

Kejenuhan basa adalah perbandingan antara jumlah kation basa yang ditukarkan dengan Kapasitas tukar kation (KTK) tanah yang dinyatakan dalam persen. Tanah dilokasi penelitian di lahan kering Kabupaten Pidie memiliki nilai kejenuhan basa dari rendah sampai sangat rendah dengan nilai rata-rata tertinggi 0,31\% sampai 0,07\%. Menurut Bohn et al.(2009), nilai KTK tanah biasanya berbanding lurus dengan $\mathrm{KB}$ tanah, karena kejenuhan basa merupakan gambaran tingginya jumlah kation pada kompleks koloid tanah. Pernyataan ini bertolak belakang dengan hasil penelitian ini. Hal ini diduga pada tanah lokasi penelitian mengalami banyak pencucian kation-kation basa di dalam tanah. Menurut Hardjowigeno (1995) pada umumnya kation-kation basa mudah tercuci, sehingga tanah dengan kejenuhan basa tinggi menunjukkan bahwa belum banyak mengalami pencucian. 


\section{Kadar C-organik Tanah}

Hasil penetapan kadar $\mathrm{C}$ organik pada lokasi penelitian di lahan kering Kabupaten Pidie bervariasi dari sangat rendah sampai sedang dengan persentase nilai rata-rata yaitu, 2,03\% sampai yang yang terendah yaitu, $0,75 \%$. Menurut penelitian yang dilakukan oleh Musthofa (2007) bahwa kandungan bahan organik harus dipertahankan tidak kurang dari $2 \%$. Jika dilihat kandungan $\mathrm{C}$ organik pada setiap jenis tanah di lokasi lahan kering Kabupaten Pidie menujukkan rata-rata < $2 \%$ masih tergolong rendah. Hal ini diduga disebabkan perbedaan kondisi iklim, curah hujan serta vegetasi daerah tersebut sehingga dapat mempengaruhi ketersediaan bahan organik di dalam tanah. Kandungan $\mathrm{C}$ organik rendah secara tidak langsung menunjukkan rendahnya produksi bahan organik pada tanah penelitian, karena bahan organik tanah merupakan salah satu parameter yang menetukan kesuburan tanah.

\section{Kandungan Phosfat ( $\mathrm{P}_{2} \mathrm{O}_{5}$ total )}

Hasil pengukuran kandungan fospor tanah dari masing-masing lokasi lahan kering Kabupaten Pidie kandungan $\mathrm{P}_{2} \mathrm{O}_{5}$ total bervariasi dari sedang sampai sangat tinggi dengan nilai rata-rata tertinggi berkisar yaitu, $521,50 \mathrm{mg} / 100 \mathrm{~g}$ sampai yang yang terendah yaitu, $46,00 \mathrm{mg} / 100 \mathrm{~g}$. Jumlah phosfat di dalam tanah sangat bervariasi tergantung pada jenis tanahnya tetapi pada umumnya rendah (Handayanto dan Hairiyah). Kandungan $\mathrm{P}$ total didaerah penelitian tidak ditemukan adanya kandungan Phospat yang rendah pada setiap jenis tanahnya yang menyebabkan faktor pembatas atau kendala kesuburan tanah di lokasi lahan kering Kabupaten Pidie sehingga tidak diperlukan penambahan cadangan fosfor ke dalam tanah.Unsur- Unsur P di dalam tanah berasal dari bahan organik (Pupuk kandang dan sisa-sisa tanaman), pupuk kimia (TSP) dan mineral-mineral di dalam tanah (apatit) (Hardjowigeno, 2003).

\section{Kandungan Kalium $\left(\mathrm{K}_{2} \mathbf{O}\right)$}

Hasil pengukuran kandungan kalium tanah dari lokasi penelitian di lahan kering Kabupaten Pidie kandungan $\mathrm{K}_{2} \mathrm{O}$ total tanah pada setiap jenis tanahnya dari rendah sampai sangat tinggi dengan nilai rata-rata $170,00 \mathrm{mg} / 100$ sampai 15,4 $\mathrm{mg} / 100$ g. Tingginya nilai Kalium tanah pada tanah penelitian disebabkan karena nilai KTK pada setiap jenis tanah di daerah penelitian tinggi. Kapasitas tukar kation yang makin besar meningkat kemampuan tanah untuk menahan $\mathrm{K}$, dengan demikian larutan tanah lambat melepas $\mathrm{K}$ dan menurunkan potensi pencucian, sehingga terjadinya penumpukan $\mathrm{K}$. Kalium yang tersedia menumpuk dalam tanah berkelembaban lebih kering tanpa ada pencucian sehingga di dalam tanah K tergolong tinggi Foth, (1994). Menurut Hakim et al., (1986) bahwa kalium yang tersedia hanya meliputi 1-2\% dari seluruh kalium yang terdapat pada kebanyakan tanah mineral sehingga tidak memerlukan pupuk kalium bahkan untuk hasil panen yang tinggi.

\section{Evaluasi Status Kesuburan Tanah}

Menurut Poerwowidodo, (1992) Kesuburan tanah adalah kemampuan suatu tanah untuk menyediakan unsur hara, pada takaran dan keseimbangan tertentu 
secara berkesinambungan, untuk menunjang pertumbuhan suatu jenis tanaman pada lingkungan dengan faktor pertumbuhan lainnya dalam keadaan menguntungkan. Sutedjo (2002) menambahkan tanah yang subur memilliki ketersediaan unsur haranya yang tersedia bagi tanaman cukup dan tidak terdapat faktor pembatas dalam tanah untuk pertumbuhan tanaman. Status kesuburan tanah merupakan kondisi kesuburan tanah di tempat dan waktu tertentu yang dinilai berdasarkan kriteria baku parameter kesuburan tanah sesuai petunjuk teknis evaluasi kesuburan tanah. Pusat Penelitian Tanah, PPT Bogor 1995. (Susila, 2013)

Berdasarkan penentuan status kesuburan tanah didasarkan pada petunjuk teknis evaluasi kesuburan tanah pusat penelitian Tanah, Bogor (PPT,1995) yang disajikan Tabel 9. Menunjukkan penilaian status kesuburan keseluruhan lahan kering di Kabupaten Pidie pada setiap jenis tanahnya adalah status kesuburan rendah. Rendahnya status kesuburan pada lokasi penelitian disebababkan karena adanya faktor pembatas yaitu rendahnya kandungan $\mathrm{C}$ organik tanah dan kejenuhan basa tanah.

Kandungan $\mathrm{C}$ organik (bahan organik) tanah sangat berpengaruh terhadap kemampuan tanah dalam mempertahankan kesuburan dan produktifitas tanah melalui aktivitas organisme tanah, banyak sifat-sifat tanah baik fisik, kimia dan biologi tanah secara langsung dan tidak langsung dipengaruhi oleh bahan organik. Bahan organik juga berperan dalam pembentukan agregat tanah (Munandar, 2013). Penambahan organik mutlak harus diberikan karena bahan organik tanah sangat berperan penting dalam menciptakan kesuburan tanah (Tolaka, 2013). Selanjutnya Kejenuhan basa tanah selalu dihubungkan sebagai petunjuk mengenai kesuburan sesuatu tanah. Kemudahan dalam melepaskan ion yang dijerap untuk tanaman tergantung pada derajat kejenuhan basa.Tanah sangat subur bila kejenuhan basa $>80 \%$, jika kejenuhan basa antara 50-80\% kesuburan tanahnya sedang dan tanah tidak subur jika kejenuhan basa $<50 \%$.

\section{KESIMPULAN DAN SARAN}

Status Kesuburan di lahan kering Kabupaten Pidie pada setiap jenis tanahnya adalah rendah.

Parameter kesuburan yang menjadi kendala dalam status kesuburan tanah di lokasi pada setiap jenis tanahnya di lahan kering Kabupaten Pidie dalah C-organik tanah dan Kejenuhan basa yang rendah.

\section{DAFTAR PUSTAKA}

Abdurachman, A., Umi H., dan Ishak J. 2006. Penetapan Kadar Air Tanah dengan Metode

Balai Penelitian Tanah - Badan Penelitian dan Pengembangan Pertanian. 2009. Perangkat Uji Tanah Kering (PUTK). Departemen Pertanian.

Besar Penelitian dan Pengembangan Sumberdaya Lahan Pertanian. Badan Penelitian dan

Bohnet, Bernd. 2009. Efficient parsing of syntactic and semantic dependency structures. In Proceedings of CoNLL-09.

Foth. H. D. Dan L. N. Turk, 1999. Fundamentals of Soil Science, Fifth Ed. John Waley \& Sons, New York. 
Gravimetrik. Dalam: Kurnia, U. (eds.). Sifat Fisik Tanah dan Metode Analisisnya. Balai

Hakim, N., M. Y. Nyakpa, A. M. Lubis, S. G. Nugroho, M. R. Saul, M. A. Diha, Go Ban Hong dan H.H. Bailey. 1986. Dasar-dasar Ilmu Tanah. Universitas Lampung, Lampung

Handayanto,E.Hairiyah,K.2007.Biologi Tanah Landasan Pengelolaan Tanah Sehat. Pustaka Adipura.

Hardjowigeno, S. 1995. Ilmu Tanah. Akademi Pressindo, Jakarta

Hardjowigeno. S, 2003. Ilmu Tanah. Akademika Pressindo, Jakarta

Melsted, S.W., and T.R. Peck. 1972. The principles of soil testing. In L.M.Walsh and J.D. Beaton (Eds.). Soil Testing and Plant Analysis. Soil Science Society of America. Inc. Madison, Wisconsin.

Mustofa A. 2007. Perubahan sifat fisik, kimia dan biologi tanah pada hutan alam yang diubah menjadi lahan pertanian di kawasan taman nasional gunung leuser. [sripsi]. Bobor: Fakultas Kehutanan Institut Pertanian Bogor Pengembangan Pertanian. Departemen Pertanian, Bogor. Hal 131-142.

Poerwowidodo. 1992. Telaah Kesuburan Tanah. Angkasa. Bandung.

PPT, 1995. Petunjuk Teknis Evaluasi Kesuburan Tanah. Laporan Teknis No.14. Versi 1,0.1. REP II Project, CSAR, Bogor.

Sukisno, K. S. Hindarto, Hasanuddin, dan A.H. Wicaksono. 2011. Pemetaan Potensi dan status Kerusakan Tanah untuk Mendukung Produktifitas Biomassa di Kabupaten Lebong. Program Studi Ilmu Tanah, Fakultas Pertanian UNIB.

Suriadikarta et al., 2002 Suriadikarta, D.A., T. Prihatini, D. Setyorini, dan W. Hartatiek. 2002. Teknologi pengelolaan bahan organik tanah. hlm. 183-238. Dalam Teknologi Pengelolaan Lahan Kering Menuju Pertanian Produktif dan Ramah Lingkungan. Pusat Penelitian dan Pengembangan Tanah dan Agroklimat, Bogor.

Susila, Dharma K. 2013. Studi Keharaan Tanaman dan Evaluasi Kesuburan Tanah di Lahan Pertanian Jeruk Desa Cenggiling, Kecamatan Kuta Selatan. Agrotrop Vol.3 No.2 Hal 13-20.

Sutedjo,M,M. , Kartasapoetra, A, G. ,Sastroatmodjo, S. Mikrobiologi Tanah,1996. PT. Rhineka Cipta,Jakarta.

Tolaka, W. 2013. Sifat Fisik Tanah pada Hutan Primer, Agroforestri dan Kebun Kakao di Subdas Wera Saluopa, Desa Leboni, Kecamatan Pamina, Peselemba Kabupaten Poso. Jurusan Kehutanan, Fakultas Kehutanan, Universitas Tadulako. Warta Rimba Vol 1 No.1

Yuke Prabansari dan Hadri Kusuma. 2005. Faktor-Faktor Yang Mempengaruhi Struktur Modal Perusahaan Manufaktur Go Public Di Bursa Efek Jakarta. Sinergi Edisi Khusus on Finance. 